\title{
To Know Them is to Love Them
}

\author{
Eugene Hunn
}

Author address: Department of Anthropology, University of Washington, Seattle, WA, U.S.A. Email: enhunn323@comcast.net

Received: December 10, 2014

Volume: 5:146-150

Published: December 30, 2014

(C) 2014 Society of Ethnobiology

Abstract: I connect the theoretical emphasis that motivated the cognitive ethnobiology of the 1960s and early 1970s with the contemporary emphasis on promoting ethnobiology as contributing to biodiversity conservation. I use the words of a popular song to highlight the necessary, if problematic, links between knowing nature - the focus of cognitive ethnobiology, loving nature, and acting to conserve nature. I argue that a highly elaborated knowledge of the living things in one's local environment is characteristic of Indigenous and other deeply rooted communities, which are dependent on sustainable harvests of local natural resources. Furthermore, this extensive knowledge goes hand in hand with a deep emotional engagement with those species ("love"), which is in turn powerful motivation to treat those species with respect, absent dominance of profit motives. I suggest in conclusion that ethnobiology may best contribute to biodiversity conservation by documenting the detailed knowledge of and cultural appreciation for biodiversity evident in such rooted communities - an effort that has defined the ethnobiological project for over the past half century. The wider community of activists dedicated to biodiversity conservation may thus better know and thus appreciate - respect, if not "love" - those who live with and depend for their livelihood on this biodiversity.

Keywords: Ethnobiology, conservation biology, classification and nomenclature, knowledge and emotion, applied ethnobiology

\author{
"To know, know, know him is to \\ love, love, love him; \\ Just to see him smile makes my life \\ worthwhile...." \\ -Phil Spector
}

This pop song by the Teddy Bears climbed to \#1 on the Billboard's Top 100 in September 1958, the lyric inspired by a tombstone epitaph (http:// en.wikipedia.org/wiki/To_Know_Him_Is_to_Love_Him). I recalled the tune as I contemplated my assigned topic for this brief perspective piece: "Cognitive Ethnobiology and Bio[cultural diversity Conservation." How so? And what has love got to do with it? How are we to connect cognitive ethnobiology - what I have characterized in a previous essay as "Ethnobiology II" (Hunn 2007), noted for its sometimes obsessive concern with nomenclature and classification - with an emergent Ethnobiology V (Wyndham et al. 2011; Wolverton 2013), which would build on what we have learned through the previous four phases of ethnobiology in order to promote a more loving relationship between humanity and biodiversity? This question is relevant to the larger issue of how we might better communicate to a broader audience the relevance of ethnobiology to the ecological and political crises that threaten us all today. I have no easy answers but a few reflections.

Cognitive ethnobiology was defined by theoretical issues of central concern in the 1960s, notably, how best to define "culture" as the proper subject of anthropological understanding. We hoped to devise a "Theory of Culture," "culture" understood as a society's "knowledge of the world." Cognitive ethnobiology traces an intellectual pedigree to an emerging "Science of Mind," which had parallel contemporary elaborations in psychology and linguistics (Gardner 1986). The recent "White House Brain Initiative: Brain Research Through Advancing Innovative Neurotechnologies," initiated to explore the "new frontier" of the human mind, indicates that our interest in understanding the cognitive foundations of culture through ethnobiological classification was not misplaced. However, anthropology's theoretical efforts since have been redirected, leaving the cognitive terrain to neurotechnology.

The ecological issues that have dominated 
subsequent phases of ethnobiological investigation were below the theoretical horizon during my grad school days. While we turned our attention inward to the "mind," we were not unaware of the essential fact that knowledge of the world derives from an engagement with the world outside the mind. We reasoned that words named ideas, that ideas were the grist for thought, and that thought was the foundation for action (D'Andrade 1995). Thus, to understand how people related to their natural environment it would first be essential to understand how people conceptualized that environment, to appreciate their traditional or local environmental knowledge (TEK or LEK, Traditional/Local Environmental/Ecological Knowledge), made manifest in language. In this we affirmed the conclusion of eminent biologists, who argued likewise that the systematic naming and classification of the world's biological species was prerequisite to any proper investigation of the evolutionary and ecological relationships among those species (Simpson 1961).

Knowledge, however, is no simple reflection of the surfaces of the world but rather involves an implicit and likely innate "theory of nature." Language, notably encapsulated in vocabulary, provides strong evidence for the mental transformations that give rise to the conceptual worlds we all inhabit. It is now apparent, in light of this early ethnobiological research, that the living world that surrounds us, the plants, animals, and fungi, is the subject of impressive lexical elaboration in all the world's languages, not least of all, those lacking written traditions. A careful study of any such language will yield an inventory of at least 1000 lexemes naming "folk species" known locally (Berlin 1992). These basic vocabulary entries constitute perhaps $5 \%$ of the total working vocabulary of a language. Such linguistic resources allow people to describe, remember, understand, and imagine their ambient biodiversity.

During the heyday of cognitive ethnobiology we were not entirely unconcerned with how this elaborate knowledge of ambient biodiversity might be of use in the everyday lives of the people with whom we worked. Claude Levi-Strauss famously discounted utilitarian motives for the elaboration of cultural knowledge, and of environmental knowledge in particular (1966), attributing the primary motivation to "disinterested" curiosity, to biophilia one might say (Wilson 1984). He rejected Malinowski's utilitarian argument that, "The road from the wilderness to the savage's [sic.] belly and consequently to his mind is very short" (1974:44). However, there is no fundamental conflict between seeing human knowledge as intellectually satisfying and at the same time useful. In fact, evolutionary theory requires that this intensive human investment in the cognitive ordering of the living world must have or have had survival value. Which brings us back to the topic of this paper: How might cognitive ethnobiology inform biodiversity conservation, in light of the fact that conservation biologists have been slow to recognize the complex intimacy of the human relationship to nature (Rozzi 1999; Saslis-Lagoudakis and Clarke 2013; Wolverton et al. 2014)?

My title hints at an answer. Do we humans treasure what we know best? Perhaps, yet it is clearly inadequate as an explanation of why humans sometimes husband living resources and at other times mercilessly exploit or destroy them. We may well grant the inverse, to wit, that to be ignorant of the plants, animals, and fungi in our midst is to guarantee that we will lack the motivation to conserve them. Even if our ignorance were only partial, say to the extent that we recognized trees, but not oaks, maples, cedars, ceibas, or baobabs; birds, but not ravens, eagles, chickadees, or hummingbirds; and mushrooms, but not morels, chanterelles, puff balls, or fly agaric, we would have next to no basis for valuing the diversity of trees, birds, and fungi. The stunning ignorance of local biodiversity demonstrated by contemporary college students (Medin et al. 2006) may be symptomatic of a modern malady, dubbed by Loev, "Nature Deficit Disorder" (2005), which in turn may account for a lack of passion in defense of the local natural environment by the earth's predominantly urban populations.

That simply knowing biodiversity - recognizing and naming hundreds of ethnospecies - ensures that we therefore will love biodiversity, is far from selfevident. There is more to the equation of knowing with loving. Our hit song suggests a somewhat more complex set of connections. First, "to know him is to love him" implies that knowing $\rightarrow$ loving, then "just to see him smile, makes my life worthwhile" implies further that loving $\rightarrow$ a life worth living. What might ethnobiology suggest with regard to these lyrical connections?

1) Our efforts at documenting the depth and breadth of traditional environmental/ ecological knowledge constitute, in my 
opinion, ethnobiology's deepest and most lasting contribution to environmental science. Our research efforts have shown that our citizen colleagues, those who are Indigenous and/or otherwise deeply engaged with local ecologies, pay close attention to the living world around them. They devise systematic inventories of local species of plants, animals, and fungi, as well as elaborating complex ethnoanatomical, ethnomedical, and ethnogeographic vocabularies. These cultural inventories of biodiversity are more than bland lists of names. Rather, each name points to a web of knowledge of where, when, how, and why a plant or animal or fungus exists, a "subtle ecology" (Wyndham 2009) of "ecological understanding" (Turner and Berkes 2006). The Zapotec children who taught me about the natural environment of their Mexican town would readily rattle off several hundred Zapotec plant names but also were eager to share many salient details about the lives of each plant and its value as food, medicine, material, or "as ornament" (Hunn 2008).

2) Given that humans are eminently capable of and inclined to carefully observe ambient biodiversity, developing thereby an encyclopedic cultural inventory of the local biota, what is the evidence that humans consequently harbor strong emotional attachments to their natural worlds? Eugene Anderson's theme throughout his Ecologies of the Heart (1996) is that to conserve nature we must first love nature, that is, feel strong emotional attachments to plants, animals, even fungi. Kay Milton likewise argues that Loving Nature is key to saving the natural world (2002). It must be recognized that beside biophilia runs a countercurrent of biophobia. Our contemporary urban aversion to mosquitoes, ticks, spiders, snakes, bats, and rats (Nolan and Robbins 2001; Nolan et al. 2006) is shared to some degree in Indigenous communities, as shown by traditional classifications of "wugs" and "noxious invertebrates," as I found in my Tzeltal Mayan ethnotaxonomies (Hunn 1977). Tzeltal Maya from Tenejapa, Chiapas, Mexico, elaborate their classification of insects to the greatest degree in dealing with social hymenoptera, ants, bees, and wasps, not so much in recognition of their beauty or positive utility but rather because of the competitive and often painful interactions with these creatures in their daily lives. Brightman characterizes the Cree attitude towards animals as a mix of respect for a worthy adversary and fear, rather than "love," with its sentimental connotations (1973). Hunters hunt their prey, kill and eat them. But, with due respect (Nelson 1983). A world apart from the "love" of the animal rights activist. Yet, time and again we learn that Indigenous people recognize the essential part each animal and plant must play in the local ecological drama. So "love" may not be the most appropriate term for this term of the equation. Rather, call this an intensely respectful emotional engagement with nature. What many urbanites have lost - insulated as many of us are from direct personal experience of nature - is this intense emotional engagement, which is replaced by ignorance, indifference, annoyance, romantic delusion, or abstract analysis.

3) Finally, can we show that this "love," this intense emotional engagement grounded in extensive, experiential knowledge will "make our lives worthwhile"? That is, will this emotion motivate action with respect to sustainable use and management of local biodiversity? We should not expect people to conserve biodiversity for its own sake. Such is far too abstract a target for "love." Rather, our most intense emotional engagements will be with particular animals or plants, places and landscapes. And such engagements are as particular as the multitude of animals, plants, and places for which we have names. Spotted Owls are easier to love (and to hate, if you were an unemployed logger) than an Old Growth forest ecosystem. Might it be the case that our inclination to conserve biodiversity is a function of the number and intensity of our emotional attachments with the world around us, grounded in direct personal experience with the stunning diversity of natural forms?

We have no controlled double-blind experimental studies that might prove that for an individual to know more about his or her ambient biodiversity guarantees or even encourages more careful steward- 
ship of that biodiversity (but cf. Atran et al. 2004; Dombrosky and Wolverton 2014). Yet anecdotally, in our contemporary urban milieu those most supportive of biodiversity conservation are those who have invested in learning to appreciate that biodiversity in concrete detail. I include here hunters and fisher folk as well as birders and native plant people. We may question this as a general rule in light of the fact that commercial fishers and foresters, however knowledgeable, have contributed to the depletion of global fish stocks and old growth forests. Two competing forces are at work here, appreciation versus accumulation. The fact that most Indigenous communities still practicing a traditional "subsistence economy" on their ancestral lands exhibit highly elaborated TEK may be due to the near absence of profit motives from their conceptual worlds, motives that drive boundless accumulation. In which case, conservation biologists should clearly recognize as their opponent not the subsistence farmer or fisher but rather the profit-making enterprises of high capitalism, a cautionary fact for proponents of the "New Conservation" (Wolverton et al. 2014; http://www.snap.is/ magazine/new-conservation-friend-or-foe/). This highlights a critical problem: The world is rapidly urbanizing. Capitalist "rationality" rules politics. Yet, somehow we must reclaim that essential basis for biodiversity conservation, the "love" of nature shared by those who live within its intimate embrace.

Finally, our equation here of knowledge $\rightarrow$ love $\rightarrow$ action may be interpreted from a different perspective. That is, it applies not only to the Indigenous and other locally rooted communities we have been inclined to study, but to ourselves (Nabhan 2013). That is, as ethnobiologists we have come to know well people who live in close proximity to and in deep dependence upon their local natural environments (Lepofsky and Feeney 2013). Participant observation over an extended period of collegial research in such communities forges an intense emotional engagement (Turner and Berkes 2006), which in turn urges our efforts on their behalf, to deflect those social, economic, and political forces that would undermine the foundations of their lives and livelihoods. My cognitive ethnobiological research masked a hidden motive. As an avid birder I took pleasure in sharing my enthusiasm for the fascinating diversity of birds with Indigenous colleagues, though they often seemed more interested in bugs and plants than birds. Thus my knowledge and love of birds led me to share an intense emotional engagement with my Indigenous interlocutors and ultimately to share this with students and colleagues. As ethnobiologists we return from the intense experience of participating with a local community, sharing in their daily encounters with nature, loving the people as they love the land. We then do our best to communicate, by writing and teaching, both our knowledge and our love of "our people." I believe this has been and will be the most effective way for ethnobiologists to promote biocultural diversity, through the medium and message of our close encounters with the citizen scientists whose lives we briefly share, at their homes in the communities we study.

\section{References Cited}

Anderson, E. N. 1996. Ecologies of the Heart: Emotion, Belief, and the Environment. Oxford University Press, New York and Oxford.

Atran, S., D. Medin, and N. Ross. 2004. Evolution and devolution of knowledge: a tale of two biologies. Journal of the Royal Anthropological Institute 10: 395 -420 .

Berlin, B. 1992. Ethnobiological Classification: Principles of Categorization of Plants and Animals in Traditional Societies. Princeton University Press, Princeton, New Jersey.

Brightman, R. A. 1973. Grateful Prey: Rock Creek Human-Animal Relationships. University of California Press, Berkeley and Los Angeles.

D'Andrade, R. G. 1995. The Development of Cognitive Anthropology. Cambridge University Press, Cambridge, UK:

Dombrosky, J., and S. Wolverton. 2014. TNR and conservation on a university campus: a political ecological perspective. PeerJ 2: e312 http:// dx.doi.org/10.7717/peerj.312

Gardner, H. 1985. The Mind's New Science: A History of the Cognitive Revolution. Basic Books, New York.

Hunn, E. S. 1977. Treltal Ethnozoology: The Classification of Discontinuities in Nature. Academic Press, New York and London.

Hunn, E. S. 2007. Ethnobiology in four phases. Journal of Ethnobiology 27: 1-10.

Hunn, E. S. 2008. A Zapotec Natural History: Trees, Herbs, and Flowers; Birds, Beasts, and Bugs in the Life of San Juan Gbëe. University of Arizona Press, Tucson. 
Lepofsky, D., and K. Feeney. 2013. Ten principles of ethnobiology: an interview with Amadeo Rea. In Explorations in Ethnobiology: The Legacy of Amadeo Rea, M. Quinlan, and D. Lepofsky, editors, pp. 34-46. Society of Ethnobiology, Denton, TX.

Levi-Strauss, C. 1966. The Savage Mind. Weidenfeld and Nicholson, London.

Loev, R. 2005. Last Child in the Woods. Algonquin Books, Chapel Hill, North Carolina.

Malinowski, B. 1974 (1925). Magic, Science, and Religion. Souvenir Press, London.

Medin, D., N. Ross, and D. Cox. 2006. Culture and Resource Conflict: Why Meanings Matter. Russell Sage Foundation Publications, New York.

Milton, K. 2002. Loving Natures: Towards an Ecology of Emotion. Routledge, London and New York.

Nabhan, G. P. 2013. Ethnobiology for a diverse world: autobiology? The traditional ecological, agricultural and culinary knowledge of us!. Journal of Ethnobiology 33: 2-6.

Nelson, R. K. 1983. Make Prayers to the Raven: $A$ Koyukon View of the Northern Forest. University of Chicago Press.

Nolan, J. M., and M. Robbins. 2001. Emotional meaning and the cognitive organization of ethnozoological domains. Journal of Linguistic Anthropology 11: 240-249.

Nolan, J. M., K. E. Jones, K. W. McDougal, M. J. McFarlin, and M. K. Ward. 2006. The lovable, the loathsome, and the liminal: .emotionality in ethnozoological cognition. Journal of Ethnobiology 26: 126-138.

Rozzi, R. 1999. The reciprocal links between evolutionary-ecological sciences and environmental ethics. Bioscience 49: 911-921.
Saslis-Lagoudakis, C. H., and A. C. Clarke. 2013. Ethnobiology: the missing link between ecology and evolution. Trends in Ecology and Evolution 28: 67-68.

Simpson, G. G. 1961. Principles of Animal Taxonomy. Columbia University Press, New York.

Turner, N. J., and F. Berkes. 2006. Coming to understanding: developing conservation through incremental learning in the Pacific Northwest. Human Ecology 34: 495-513.

Wilson, E. O. 1986. Biophilia. Reprint Edition. Harvard University Press, Cambridge, Massachusetts.

Wolverton, S. 2013. Ethnobiology 5: interdisciplinarity in an era of rapid environmental change. Ethnobiology Letters 4: 21-25.

Wolverton, S., J. M. Nolan, and W. Ahmed. 2014. Ethnobiology, political ecology, and conservation. Journal of Ethnobiology 34: 125-152.

Wyndham, F. S. 2009. Spheres of relation, lines of interaction: subtle ecologies of the Rarámuri landscape in northern Mexico. Journal of Ethnobiology 29: 271-295.

Wyndham, F. S., D. Lepofsky, and S. Tiffany. 2011. Taking stock in Ethnobiology: Where do we come from? What are we? Where are we going? Journal of Ethnobiology 31: 110-127.

\section{Biosketch}

Eugene Hunn is professor emeritus of anthropology at the University of Washington. He has served as president of the Society of Ethnobiology and editor of the Journal of Ethnobiology. He was honored as a Distinguished Ethnobiologist by the Society of Ethnobiology in 2014. 